\title{
Open social innovation for surplus food recovery and aid during COVID-19 crisis: the case of Fondazione Banco Alimentare Onlus
}

\author{
Lara Penco, Andrea Ciacci, Clara Benevolo and Teresina Torre \\ University of Genoa, Genoa, Italy
}

\begin{abstract}
Purpose - The study analyses the role that open social innovation (OSI) perspective played for Fondazione Banco Alimentare Onlus (FBAO), a food bank in Italy, in responding to the COVID-19 crisis. It answers the following research question: how does a crisis, such as the COVID-19 pandemic, stimulate the adoption of OSI practices to revamp the activities of FBAO and facilitate appropriate solutions to carry out its social mission? Design/methodology/approach - This study employs a qualitative approach. It is based on a single case study.

Findings - The study shows how COVID-19 has stimulated the adoption of OSI practices to continue to meet the social mission, creating innovative projects or finding new ways to do the same things.

Research limitations/implications - The study is based on a single case study.

Practical implications - The paper contributes insights into the literature on OSI, examining how inbound and outbound OSI mechanisms can modify business models and increase the adaptation capacity of food banks and their effectiveness. In addition, it provides a rich context in which the social value drivers provided by OSI are studied.

Originality/value - This paper applies the OSI to a food bank to evaluate what this action mode produces for the food bank during a health crisis. Specifically, this is the first paper that studies the COVID-19 crisis response of a food bank from the OSI perspective, focusing on the inbound and outbound OSI processes that characterized the entire network of relationships.
\end{abstract}

Keywords Open social innovation, Food banks, COVID-19, Crisis

Paper type Research paper

\section{Introduction}

The rapid outbreak of the COVID-19 pandemic has triggered an alarming global health crisis (Kraus et al., 2020). In the absence of effective short-term medical responses to the virus (the ongoing vaccine or other treatments), several regions and entire countries have been entirely locked down with the implementation of a full curfew (Ferguson et al., 2020). The restrictions have not only impacted the economic activities, producing a simultaneous demand and supply shock (Anderson et al., 2020), but they have also had a dramatic social impact. The COVID-19 crisis has affected the entire food supply chain system. Food producers have faced

(C) Lara Penco, Andrea Ciacci, Clara Benevolo and Teresina Torre. Published by Emerald Publishing Limited. This article is published under the Creative Commons Attribution (CC BY 4.0) licence. Anyone may reproduce, distribute, translate and create derivative works of this article (for both commercial and non-commercial purposes), subject to full attribution to the original publication and authors. The full terms of this licence may be seen at http://creativecommons.org/licences/by/4.0/legalcode

The authors wish to thank all the people we had the opportunity to engage with regarding the FBAO and territorial associations during the study period, particularly General Secretary Marco Lucchini, whose responses and analysis have been illuminating and have deepened our research perspective. Of course, any content of this paper is our responsibility.

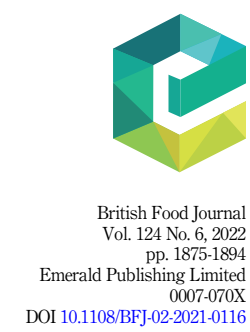


$\mathrm{BFJ}$

124,6

1876

difficulties in supplying some goods, peaks in demand for various other goods, and important changes in consumption and distribution channels (for instance, the crisis of the HoReCa, i.e. Hotel-Restaurant-Catering, channel and the increase in retail sales). Some businesses suddenly have had to reduce their activities, causing a food surplus and consequently food wastage.

At the same time, the economic crisis has caused a difficult situation for many people, further worsening the conditions for those who live under the so-called poverty threshold and devastating those who were living on the edge (Laborde et al., 2020). This problem is confirmed by the increased number of requests to charity institutions and the local governments' social services (FAO, 2020a, b). While in 2019, about $8.9 \%$ of the global population (690 million people) suffered from hunger, according to the most recent estimates of international organizations (FAO et al., 2020), this number looks set to rise due to the pandemic and bring the tally of the global victims of hunger close to the alarming 800 million mark.

During this pandemic, food banks have increased their scale of activity. Literature has studied food banks and their advantage to the entire food system (Barzeghi et al., 2016; Michelini et al., 2018). Food banks are defined as community-centred warehouses that solicit food, store food obtained from local producers, retail food sources, federal commodity distribution programs, and the food industry, and distribute it to charity institutions (Berner and O'Brien, 2004; Bazerghi et al., 2016; Nichols-Casebolt and Morris, 2002; Teron and Tarasuk, 1999). They offer win-win situations for all the involved subjects, such as the private food sector (reduced waste management and disposal costs) (Baglioni et al., 2017; Michelini et al., 2018; Principato et al., 2020; Tarasuk et al., 2014), charity organizations (accomplishment of social goals) and society as a whole (guaranteed food access to the deprived) (Midgley, 2014).

In the context of this pandemic, food banks need to adapt and expand their business models quickly, reinforce their capacity to utilize food wastage better, evolve in their processes and ensure the safety of their employees, volunteers and, that of the people operating within their networks of charities and institutions (FAO, 2020a, b). In order to meet these grand challenges, we assume that food banks have forced the open innovation (OI) approach (Annosi et al., 2020; Gassman and Chesbrough, 2010; West et al., 2006). OI is expected to play an important role in recovering from the COVID-19 aftermath and "can help speed things up" (Chesbrough, 2020). Considering the specificities of food banks, we focus on the open social innovation (OSI) perspective (Chalmers, 2012; Chesbrough and Di Minin, 2014). This research issue of how OI can contribute to social innovation, especially regarding food banks, is understudied (Rayna and Striukova, 2019). In particular, our study focuses on how OSI can help food banks innovate their business models and operations during the COVID-19 pandemic, in an attempt to answer this research question: How does a crisis, such as the COVID-19 pandemic, stimulate the adoption of OSI practices to revamp the activities of FBAO, and find appropriate solutions to carry out its social mission?

The case study on the Fondazione Banco Alimentare Onlus (FBAO) assists in answer this question. The FBAO was established in 1989 as a not-for-profit-organization with a clear mission, "Sharing needs to share the sense of life" (Art 2, FBAO Statute). It aims to create a large horizon looking to the whole person's needs, at the basis of its very concrete action and wishes to make its partners adapt to this culture and style. It is involved in surplus food recycling (Baglioni et al., 2017), focusing on the identification of the sources of food "wastage" in the agri-food chain (for example, unmarketable, or unsold products), collection and storage of goods at the warehouses of FBAO, which then have to be redistributed to charitable institutions which directly meet and assist deprived individuals.

The FBAO, like many other European food banks, is now facing new challenges due to COVID-19. The first crisis factor is directly connected to the amplification of the poverty 
matter. The National Institute of Statistics notes that 1 million people fell into a state of absolute poverty in 2020. Overall, in Italy, families in absolute poverty are more than 2 million, for a total number of individuals equal to about 5.6 million (ISTAT, 2021). The second
crisis factor is the social distancing practice (Scheidgen et al., 2021), which profoundly affects the daily operating procedures of all the organizations involved in the networking for recovery and redistribution. Considering these factors, we assume that the OSI allows the organizations operating in the social sectors to react to the COVID-19 crisis faster (Chesbrough, 2020).

This research aims to apply the OSI theoretical framework to the FBAO, since the attention devoted to jointly studying OSI and food banks is still scarce in the literature. Moreover, there is the need to cover a research gap in light of the fast and unexpected constraints brought about by the dramatic event of COVID-19. In an attempt to answer the call of Dahlander et al. (2021) for more contributions studying outbound OI, we focus on both inbound and outbound OSI to define the network system and emerging solutions enabling the capacity of the FBAO to adapt and offer responses to cope with the COVID-19 crisis and connected needs.

Our study offers the following contributions to the literature. First, we contribute to the OI and in particular to OSI literature by providing insights on how these constructs help the food banks pursue their social mission. Second, we provide a rich context in which the social value drivers provided by OSI are studied. Third, we try to clarify the entire strategy of inbound and outbound OSI formation (Dahlander et al., 2021), based on the experience of the FBAO.

This issue can also have managerial implications at an international level if we consider that at present, worldwide, three food bank networks are active, i.e. the Global Food Banking Network, Feeding America, and the Feba-European Food Bank Federation. They assist 70 different countries, feeding about 62 million people and preventing the loss of millions of tons of edible food surpluses each year (FBAO, 2020).

The remainder of this paper is organized as follows: Section 2 provides a theoretical background on the OI and OSI; Section 3 explains the research design and methodology used in this study; Section 4 describes the main empirical findings; Section 5 discusses the research; and finally, Section 6 draws theoretical and practical implications that stem from OI and OSI, along with the best managerial practices.

\section{Theoretical background}

COVID-19 has generated a crisis with deep implications for the well-being of the whole society. The actions of the entities with a social mission are crucial in mitigating social problems exacerbated by the pandemic (Bacq and Lumpkin, 2020). In response to this exogenous shock, non-profit organizations have to adopt timely changes in their modus operandi (Farhoud et al., 2021). In this regard, we consider the OSI an effective approach by which organizations can speed up the progress toward further innovation (Chesbrough, 2020). To define the theoretical concepts of our papers, the following paragraphs aim to provide an overview of the main literature on OI and OSI, introducing the main features of these constructs to help understand how they can facilitate food banks' ability to face and cope with the current crisis.

\subsection{Open innovation definition}

OI is defined as a process with distributed innovation, which involves purposive knowledge flowing across organizational boundaries for monetary or non-monetary reasons (Chesbrough, 2003; Chesbrough and Bogers, 2014). It is essential for surviving and gaining a competitive advantage in most business environments (Annosi et al., 2020; Bresciani, 2017; 
$\mathrm{BFJ}$

124,6

1878
Ferraris et al., 2020a, b; Traitler et al., 2011) and contributing to business model innovations (Chesbrough and Schwartz, 2007; Huang et al., 2013; Saebi and Foss, 2015).

OI is based on inbound and/or outbound mechanisms (Chesbrough and Crowther, 2006; Lichtenthaler et al., 2011). Specifically, inbound OI refers to how firms can use external sources of innovation. If new ideas and technologies exist, the network entities use them to model the novelties to achieve their purposes. As Rothwell wrote in 1994 (p. 19), "accessing external know-how has long been acknowledged as a significant factor in successful innovation." Outbound OI denotes how internal resources are revealed to the partners within the network (Dahlander and Gann, 2010). This process implies that firms adopt strategies to selectively reveal their novel practices to elicit collaboration (Henkel, 2006). In literature, it is a well-accepted assumption that organizations that share, increase the opportunities to gain interest from other parties (Dahlander and Gann, 2010).

Scholars have also recognized the great relevance that network collaborations assume to elicit the OI processes (West and Bogers, 2017). It has been indeed demonstrated that collaborative networks positively affect the innovative performance for various types of firms (Dittrich and Duysters, 2007; Nieto and Santamaría, 2007; Ritter and Gemunden, 2003; Zeng et al., 2010), as well as the regional innovation performance (Belussi et al., 2010; Komninos, 2004). Moving beyond the bilateral collaborations (Chesbrough, 2003), several network typologies have emerged (West et al., 2006). These forms involve alliances, communities, consortia, ecosystems and platforms. They call attention to the firms' orchestration mechanisms (Schepis et al., 2021), intended as the "set of deliberate, purposeful actions undertaken by the hub firm as it seeks to create value and extract value from the network" (Dhanaraj and Parkhe, 2006, p. 659).

Several contributions are focused on OI in the food and beverage system. In this system, the main competitive challenges involve the necessity of adapting to consumer demands, which are increasingly differentiated (Baregheh et al., 2012; Cillo et al., 2019; Penco et al., 2019), and the strongly expressed need for reliable control systems to inform consumers about quality, safety and origin of products (Garcia Martinez et al., 2014). Given the numerous parties involved in the same supply chain, as well as their difficulties in meeting customers', end-users' and legislators' requirements autonomously (Bayona-Saez et al., 2017; Bresciani, 2017), the OI process is becoming more and more vital in ensuring food competitiveness and profitability (Bigliardi and Galati, 2013; Ferraris et al., 2020b). Technologies are frequently developed outside of the food and beverage industry (for example, nanotechnology and biotechnology). This raises the importance of OI (Baregheh et al., 2012; Cillo et al., 2019; Flammini et al., 2017). Additionally, by cooperating with different partners along the same value chain, firms operating in this system can enhance their attitude toward the products and processes innovation, addressing both new demand needs and legislative issues (Cillo et al.,2019; Menke and Raith, 2017). To the best of our knowledge, no literature has been found about surplus food recovery that can aid in this perspective.

\subsection{Open social innovation}

Recent literature reports that OI has also been applied to the social sector since openness can be useful in satisfying social needs and promoting social innovation (Tardivo et al., 2017). Social innovation refers to designing and implementing creative ways of fulfilling social needs and creating better and sustainable societies (Grimm et al., 2013; Moulaert et al., 2019; Mulgan, 2006; Mumford, 2002). In literature, social innovation is seen as a powerful tool to overcome adversity affecting the most disadvantaged groups within society (Grimm et al., 2013; Rayna and Striukova, 2019). Social innovation can produce deep changes because of its widespread impact on the population (Westley and Antadze, 2010), and it can provide customized solutions to niche problems (Chalmers, 2012). 
The combination of social innovation and OI defines the Open Social Innovation (OSI) concept (Chalmers, 2012; Chesbrough and Di Minin, 2014; Rayna and Striukova, 2019). Chesbrough and Di Minin (2014) define OSI as "the application of either inbound or outbound open innovation strategies, along with innovations in the associated organization's business model, to curb social challenges" (p. 170). OSI differs from the traditional forms of social innovation since it is based on collaborative organizational structures and behaviours aimed at constantly dealing with social problems. OSI implies that organizations reveal specific sides of their knowledge and expertise to competitors, partners and customers to pursue their collaboration (Chalmers, 2012).

The OSI helps to innovate social business models, increase access to relevant resources and share them within the ecosystem of actors, thus enriching the overall positive impact on the economy, society and/or environment.

The OSI overcomes critical barriers by enabling access to external resources and skills, and creating an ecosystem in which users, corporations, and communities are connected more effectively (Gupta et al., 2017; Rayna and Striukova, 2019). In this context of interconnected elements, the network collaborations grow and refine over time, becoming determinants for achieving the success of the OSI process. OSI can help solve social needs and create new relationships or partnerships with operators who belong to different industries that are particularly critical in the last stages of the social innovation process (Randhawa et al., 2019; Rayna and Striukova, 2019). Holmes and Smart (2009) offer examples from the UK of collaborations involving corporate and non-profit entities: the innovation outcome of a partnership linking a children's charity with a communications company ensures integrated data management solutions incorporating web and telephone services; Chesbrough and Di Minin (2014) provide the case of emergency.

Despite the relevance of the problem, the research issue regarding OSI, such as the organizational context in which the OSI is fostered, is still understudied. Organizations with a social mission can employ an inbound/outbound OI to improve the spread of their ideas reciprocally (Dahlander and Gann, 2010). In these terms, social organizations that sponsor ecosystem networks must attract partners to create social value (Adner and Kapoor, 2010; Boudreau, 2010; Rohrbeck et al., 2009). Firms can utilize the networks both as an external source of innovations to acquire ideas and as a learning-oriented environment in which major dissemination of outbound innovations is made possible (Vanhaverbeke, 2006; West and Bogers, 2014).

\subsection{Open social innovation for surplus food recovery and aid}

Given the COVID-19 situation, the need for surplus food recovery and aid has become increasingly urgent (FAO, 2020). In this regard, food banks are able to stimulate the convergence toward a point of balance, reducing hunger and malnutrition, and fighting against food waste (Baglioni et al., 2017; Hermsdorf et al., 2017; Michelini et al., 2018).

In addition to this, food banks cannot overlook the challenge posed by nutritional quality and variety. Ensuring a good nutritional quality means monitoring the expiry date and the natural deterioration of food and satisfying diversified nutritional needs (Bazerghi et al., 2016; Martin et al., 2019). Resource allocation, that is the resource distribution to meet the specific demand, is a decisive operational capacity of every food bank to meet all these prerogatives (Alkaabneh et al., 2021).

All these needs have already driven the literature on the subject in recent years, leading to a significant proliferation (Cavicchi and Santini, 2014; Garrone et al., 2014; van der Horst et al., 2014).

During the COVID-19 pandemic, food banks have been called upon to respond to grand challenges that require innovation and collaboration with the entire supply chain. Concerning 
$\mathrm{BFJ}$

124,6

1880 this requirement, the impact of the COVID-19 crisis on food banks can be interpreted under the paradigm of "social innovation". At the same time, the OI paradigm is considered one of the most important weapons to find solutions to the COVID-19 crisis (Chesbrough, 2020). We assume that both social innovation and OI can contribute to framing the food banks in the COVID-19 crisis context when food banks were obliged to search for solutions to adapt to the sudden environmental changes. We argue that improving our understanding of OSI mechanism is crucial to face the many challenges of this evolutionary world.

\section{Method}

\subsection{Case study methodology}

In this work, empirical data was collected by applying a single case study approach (Cunningham, 1997; Eisenhardt and Graebner, 2007). This research method is appropriate because we do not build on previous extensive theoretical and/or empirical investigations (Glaser and Strauss, 1967) and the selected case incorporates particular characteristics that attribute the profile of uniqueness to the research topic (Yin, 1994; Siggelkow, 2007) so that we aim to corroborate theoretical developments (Eisenhardt, 1989; Dyer and Wilkins, 1991). To date, within the Italian context, there are no organizational entities comparable to the FBAO. Its size and the widespread diffusion on the national territory, and the high number of deprived people that regularly benefit from the local services provided with the essential support of the FBAO, contribute to make it an unparalleled organization with an extensive social impact. For these reasons, the case study is reliable.

Furthermore, analysing the case study longitudinally, it is possible to grasp the changes of a phenomenon in a dynamic way, focusing attention on the entire managerial, strategic and organizational process that underlies the change. This perspective is particularly suitable to study an evolving framework characterized by high environmental instability (Matricano et al., 2019; Siggelkow, 2001).

\subsection{Data collection}

Despite the FBAO case being studied over the past 20 years, we decided to focus on the specific period after the World Health Organization (WHO) classified the COVID-19 crisis as a pandemic. Considering that the events developed during these 12 months have produced social and economic shocks and consisted of rapid evolutions and changes, we consider this timeframe appropriate for analysing the case longitudinally.

In this vein, the entire data collection phase lasted from March 2020 to February 2021 and involved both the FBAO and the local territorial associations. It has been developed through direct (interviews and personal contact with informants) and indirect sources (websites, news). The onset of the COVID-19 pandemic moved the focus of the interviews toward the changing process of OSI, necessitating the content of each interview to depend on the specific situation of the FBAO facing the pandemic crisis. We used the OSI conceptualization to define the boundaries and the main objects of interest of the interviews. To understand the OSIbased strategic response to COVID-19, the apical data sources were interviews with the General Secretary, whose knowledge is the deepest on the issue, owing to his participation in the entire lifecycle of the FBAO. He was asked about:

(1) The description of the situation (the trigger event), the actions undertaken, and the new collaborations launched;

(2) The perceived facilitators and barriers that the network of the FBAO and the local networks activated by the territorial associations had encountered in pursuing the mission they share;

(3) The role of partnership in reactive and proactive behaviours. 
In addition, interviews with three managers of the territorial associations (located in the north west, north-east, and south of Italy) were conducted. Moreover, over the last few months (for most, this was January 2021), they were invited to submit short audio diaries (audio messages). These participants were encouraged to describe the FBAO and the local network activated by the territorial associations during the past months. In February, the final interview was held with the Secretary, in which the initial project findings were discussed.

The interviews were held through virtual meeting platforms; on average, each interview lasted for about $90 \mathrm{~min}$. All interviews were audio-recorded, transcribed (the transcription of the interviews took place as soon as possible after having concluded the interviews), and translated from Italian to English. They were independently analysed by each of the authors and discussed to reduce subjectivity in interpreting the data. E-mails and telephone sessions were organized when we realized some crucial information was lacking. Table 1 presents the data sources employed over the study period.

These data points were triangulated with secondary data taken from various sources. All data were analysed following the protocols for qualitative data analysis (Eisenhardt and Graebner, 2007). Next, we examined the results to obtain coherence and reinforced our knowledge. Owing to the longitudinal approach, however, we reworked primary and secondary information.

\section{Results and main findings}

\subsection{Setting the ground: the nature of the network of the FBAO}

FBAO coordinates and leads a network consisting of 21 territorial associations of Banco Alimentare, that have direct relationships and agreements with local charity institutions throughout Italy, supporting them in focusing on their core business (Santini e Cavicchi, 2014). At the same time, in force of their local presence, the territorial associations implement direct actions towards food companies and supermarket chains to identify new sources of waste and recovery, and enrich food availability. Coherently, with its guiding role and governance, the FBAO manages the core of the business strategy. It owns the brand and nurtures main relationships at the national and international levels (for example, the European Union). The FBAO also promotes a food wastage recovery culture (Benevolo and Caselli, 2000) because family food waste accounts for a significant share of the total food

\begin{tabular}{|c|c|c|}
\hline Source & $\begin{array}{l}\text { March 2020-February } 2021 \\
\text { Type of data }\end{array}$ & Use in analysis \\
\hline $\begin{array}{l}\text { Semi-structured } \\
\text { interviews }\end{array}$ & $\begin{array}{l}\text { Two semi-structured interviews with the } \\
\text { general secretary of the FBAO ( }+ \text { follow up) } \\
\text { and three semi-structured interviews with } \\
\text { managers of local associations }\end{array}$ & $\begin{array}{l}\text { Tracking the evolution of FBAO } \\
\text { during the pandemic } \\
\text { Defining the OSI processes during the } \\
\text { entire period of analysis }\end{array}$ \\
\hline Informal contacts & $\begin{array}{l}\text { Informal discussions with local representatives } \\
\text { and volunteers in charge for organizational } \\
\text { issues }\end{array}$ & $\begin{array}{l}\text { Understanding the operational aspects } \\
\text { of the local associations during the } \\
\text { pandemic }\end{array}$ \\
\hline $\begin{array}{l}\text { Direct } \\
\text { observations }\end{array}$ & $\begin{array}{l}\text { About of } 12 \mathrm{~h} \text { of presence for the National } \\
\text { Collection Day } 2020 \text { in the wholesale } \\
\text { supermarkets }\end{array}$ & $\begin{array}{l}\text { Identifying the most important } \\
\text { transformation of National Collection } \\
\text { Day }(2020)\end{array}$ \\
\hline Website & $\begin{array}{l}\text { News about every aspect of the life at national } \\
\text { and local level }\end{array}$ & $\begin{array}{l}\text { Investigating projects and activities } \\
\text { during the COVID-19 }\end{array}$ \\
\hline $\begin{array}{l}\text { Publications and } \\
\text { reports }\end{array}$ & $\begin{array}{l}\text { Documents produced by FBAO and other } \\
\text { subjects analysing its activities }\end{array}$ & $\begin{array}{l}\text { Tracking of changes in the strategies, } \\
\text { actions and activities during the } \\
\text { COVID-19 }\end{array}$ \\
\hline
\end{tabular}

Source(s): Our elaboration

Table 1. Source of data 
$\mathrm{BFJ}$ 124,6

waste in developed economies (FAO, 2019). The FBAO has also worked to change the Italian law context to facilitate food recovery (see Table 2 for more information about the FBAO business model).

The FBAO impact has progressively increased. The entire network distributed 200 tons of food to 20 charities in the foundation year, thereby assisting 2,000 people. In 2019, it distributed 75,449 tons of food to its 7,448 affiliated charities [1]. The estimate for 2020 was

\section{2}

\begin{tabular}{|c|c|c|c|c|}
\hline Key partners & Key activity & $\begin{array}{l}\text { Value } \\
\text { proposition }\end{array}$ & Customer relations & $\begin{array}{l}\text { Customer } \\
\text { segments }\end{array}$ \\
\hline $\begin{array}{l}\text { - Food industry } \\
\text { (producers; } \\
\text { Large retailer; } \\
\text { Restaurant; } \\
\text { Catering) } \\
\text { - Volunteering } \\
\text { - European } \\
\text { Association of } \\
\text { Food Banks } \\
\text { - Other non- } \\
\text { profit } \\
\text { organizations } \\
\text { - Public bodies } \\
\text { - Universities } \\
\text { and research } \\
\text { institutions } \\
\text { - Financial } \\
\text { Intermediaries } \\
\text { - Digital } \\
\text { providers }\end{array}$ & $\begin{array}{l}\text { - Wholesaling/ } \\
\text { intermediation } \\
\text { activity } \\
\text { - Promotion of } \\
\text { culture against } \\
\text { food waste } \\
\text { - Promotion of } \\
\text { culture against } \\
\text { poverty } \\
\text { - Identification of } \\
\text { new forms of } \\
\text { supply and } \\
\text { fight against } \\
\text { waste } \\
\text { - Maintenance of } \\
\text { the network } \\
\text { and activation } \\
\text { of new } \\
\text { partnerships } \\
\text { Accreditation of } \\
\text { regional food } \\
\text { banks } \\
\text { Key resources } \\
\text { - Brand and } \\
\text { reputation } \\
\text { Volunteers } \\
\text { - Regional } \\
\text { warehouses } \\
\text { Vehicles for } \\
\text { fresh food } \\
\text { distribution }\end{array}$ & $\begin{array}{l}\text { - Food aid: } \\
\text { fight against } \\
\text { food poverty } \\
\text { - Reduction of } \\
\text { food waste in } \\
\text { industry, } \\
\text { large } \\
\text { retailers, and } \\
\text { restaurants } \\
\text { - Reduction of } \\
\text { waste and } \\
\text { disposal } \\
\text { costs in } \\
\text { industry, } \\
\text { large } \\
\text { retailers, and } \\
\text { restaurants }\end{array}$ & $\begin{array}{l}\text { Channels } \\
\text { - Regional bank } \\
\text { association } \\
\text { - Other bodies } \\
\text { involved } \\
\text { - National Collection } \\
\text { Day } \\
\text { - National agency } \\
\text { for agricultural } \\
\text { funding (AGEA), } \\
\text { industry, big } \\
\text { retailers and } \\
\text { catering } \\
\text { - Communication } \\
\text { (website, events) }\end{array}$ & $\begin{array}{l}\text { Charity and } \\
\text { non-profit } \\
\text { organizations } \\
\text { that assist } \\
\text { needy people } \\
\text { public bodies } \\
\text { (municipalities): } \\
\text { intervention } \\
\text { alongside } \\
\text { public bodies in } \\
\text { responding to } \\
\text { emerging needs }\end{array}$ \\
\hline
\end{tabular}

Cost structure

Structure costs (salaries, website, enterprise resource planning, etc.)

Promotional and marketing activities

Table 2.

The FBAO's business model
Source(s): Our elaboration
Revenue streams

\section{Donations}

Income from cause-related marketing Research funding (public bodies and bank foundations) 
about 100,000 tons of food and 8,000 affiliated charities, demonstrating a net annual growth of the national impact of the network of the FBAO.

Some authors have studied the networks related to FBAO over the last twenty years (Benevolo and Caselli, 2000; Benevolo and Torre, 2002; Torre, 2000). These previous studies help us reinterpret the activities of the FBAO in terms of OSI. First of all, to meet its mission, the FBAO has adopted a network model which connects the focal organization (FBAO) to the territorial associations (internal network), charity communities, other different organizations, and new participants to co-develop innovative ways of pursuing the social mission (external networks). This complex and articulated network resulting from interaction among different networks acts as an OSI platform where the FBAO is the pivotal actor (Saebi and Foss, 2015). Figure 1 represents the network of the FBAO. FBAO, as a pivot, manages the intangible flows, while the territorial associations also manage physical flow of food and goods. In other words, the FBAO creates linkages with firms and institutions operating within the food system and other bodies in order to implement its mission and enlarge its scope (for example, the creation of agreements, the sharing of knowledge, information, and experience, with the actors involved in the networks), leaving to the territorial associations the specific task of organizing the processes of supply to the charity organizations.

For the entire network, combining both inbound and outbound OSI paths (Chesbrough and Crowther, 2006) is part of its nature and FBAO is the pivot. Regarding the inbound OSI, the FBAO works with firms operating in the food supply chain, startups, incubators and

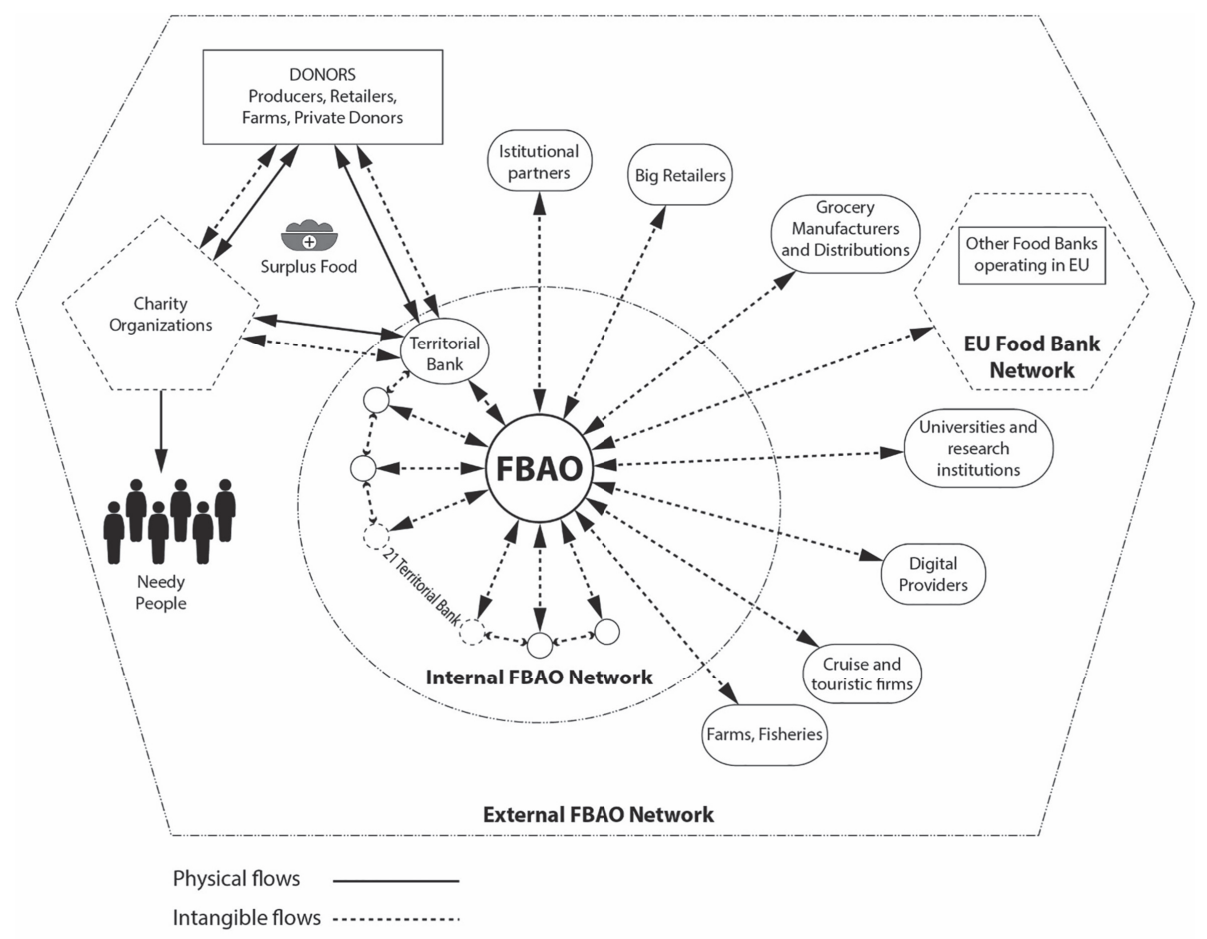

Source(s): Our elaboration

Figure 1. The network of the FBAO 
$\mathrm{BFJ}$

124,6

1884 universities to innovate its activities incrementally (for example, the digitalization of the processes).

On the other side, the network of the FBAO also implements outbound processes of OSI. Firstly, it promotes the culture and the knowledge of the surplus recovery to the entire food and beverage system, also becoming a trusted partner for the implementing of corporate social responsibility actions. Moreover, owing to the FBAO and territorial associations, charity entities are involved in the innovative processes by testing and then adopting new organizational paths; in other words, the FBAO, thanks to the role of the territorial association, activates a transfer of knowledge to the charity organizations.

In terms of inbound/outbound OSI, the FBAO organizes, every year, National Collection Day. Italian consumers/shoppers are called to charity and solidarity by the volunteers of the network of the FBAO in the partners' supermarkets throughout Italy. The donated food is redistributed to the charitable organizations related to the FBAO. Additionally, the FBAO contributed to the development and the diffusion of the start-up Bringthefood.com. Bringthefood is a web application used by various food banks and collection networks to manage surpluses from restaurants, businesses (small and large retailers), and producer organizations. Moreover, the FBAO collaborates with other external partners in EU research projects to absorb innovative procedures and involve external organizations (for example, donors and institutions) in creating new initiatives.

\subsection{COVID-19 as a trigger event: the acceleration of the OSI attitude}

The interviews reveal how the COVID-19 pandemic has been the trigger event that prompted the attitude toward OSI. Compared to the past, food surplus and poverty projects have proliferated substantially. As the General Secretary highlighted during the first interview, "The real challenge will be for everyone to be consistent in their responses [. . .] avoiding the risk to make plans with a short life".

The analysis of the interviews carried out during the COVID-19 era identified three major phases. Figure 2 provides an outline of the evolution of the network of the FBAO in terms of OSI.

In the following sub-sections, we describe each phase, and whenever useful, we use representative quotes to illustrate our interpretations.

(1) Phase 1: the reaction.

The first lockdown period corresponds to the first phase. In this period (March 2020-May 2020), the FBAO faced an unexpected situation that required reorganizing its entire service and modifying some of the existing business model pillars. There was an emergency spike in deprived people (from the interview with the south territorial association and northwest territorial association) that had lost their income because of COVID-19 (for example, selfemployed, fired people, temporary workers, and circus performers). Food donations increased and non-essential activities such as restaurants, bars, and catering services were forced to reduce their activities, causing a food surplus. Moreover, new donors emerged; for instance, the FBAO was able to start a collaboration with the Department of Penitentiary Administration to activate a collection of food that involved all prisons (each prison was invited to promote a food collection, thanks to which prisoners could allocate part of their weekly shopping). The composition of food donations changed; the closure of non-essential services (such as catering and cruises) incited "new sources of food surplus and expanded the quota of fresh food and ready meals" and several territorial associations had to invest in new refrigerators (from the interview with the north-west territorial association).

Moreover, social-distancing policies and total lockdown periods provoked a reduction in the number of volunteers, predominantly those over 65 years. In this phase, "the general 


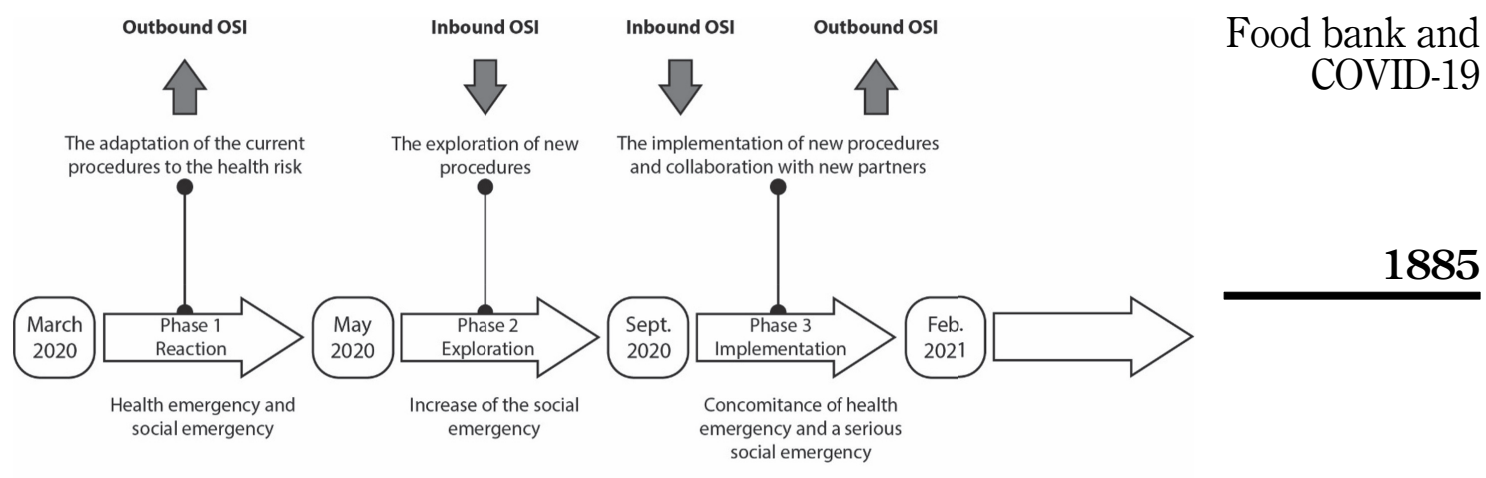

COVID-19 crisis

Figure 2.

Source(s): Our elaboration

attention was on health risks and less on socio economic problems" (from the interview with the General Secretary). This was confirmed by the three managers of the territorial Associations: "The innovation of the current procedures in order to protect all people to the health risk was the priority" (to cite one quote from the interview with the north-east territorial association).

The COVID-19 pandemic could have created barriers for implementing social innovation (Murray et al., 2010) but, in order to continue the activities, new procedures were experimented and adopted, preserving the safety of the people involved. First of all, to respond strategically to this crisis, the FBAO promoted communications with its territorial associations and participated in regular meetings with the European international network to share knowledge and experiences on the most suitable procedures. For the safety of their volunteers, each territorial association reorganized their volunteer networks to include smart working for administrative activities and the "recruitment" of younger volunteers (even as external partners) for logistics activities: "We have promoted a call for volunteers that helps to insert in our daily activity 150 new and young persons" (from the interview with the south territorial association).

Additionally, the structural distribution pipeline was inverted (from the interview of the north-west territorial association); since March 2020, the local networks activated by the territorial associations, with the help of volunteers and public institutions, managed the physical delivery of food from the wholesale stores to the final charity structures (in the past, it was the charity organization that managed the physical acquisition of food from the territorial association stores). New innovative procedures to meet the serious social needs were identified, promoting an inside-out OSI (for example, diffusion of new protocols, training for charities, volunteers and support for helping charities in difficulties to continue their work), and focusing on all charity organizations and all the donors. Considering that this emergence enlarged the audience of deprived people with a specific nutritional problem (like family with infants, or disabilities), the territorial associations rescheduled their needs and "have created teams for controlling the nutritional quality of the food distributed by the charity organizations/communities" (from the interview with the south territorial association).

To address these important missions, the formation of dedicated teams was unavoidable. Hiring new, creative, and enthusiastic personnel allowed FBAO to deploy properly trained volunteers along the various battlefields. A good solution was to hire students to meet the needs in terms of required qualities and dynamism. 
$\mathrm{BFJ}$

124,6

1886
(2) Phase 2: the exploration of new OSI patterns.

During the summer (phase 2), the socio-economic problems progressively worsened because of the increasing number of deprived people. In this phase, it became essential for the FBAO to adopt all those changes that allowed it to reach a greater number of deprived people, increasing the impact of its actions. In this regard, the FBAO increased the scale of its operations ( $+40 \%$ of food aid actions). This was made possible by a progressive improvement of inter-organizational coordination, corresponding to more intensive food inflows. The FBAO achieved a higher level of internal process optimization that managed larger amounts of acquired resources simultaneously. The FBAO confirmed itself as a firstlevel social outpost also during the COVID-19.

At the same time, the FBAO continued to evaluate external proposals and external ideas to continue to meet its social mission. In this phase of "exploration", the FBAO started to think strategically regarding the organization of the National Food Collection Day which typically occurred on the last Saturday of November. The role of inbound OSI was prominent since the entire network of the FBAO had to absorb external knowledge and learn how to do the same project in a completely new way.

(3) Phase 3: the implementation of OSI.

In the fall-winter season (phase 3), "the concomitance of the health crisis and the socio-economic crisis had occurred" (from the interview with the General Secretary). The experience had cumulated, with more attention focused on the program and "day-to-day organization" activities. The correct procedures were adopted to guarantee both the implementation of the social mission and the safety of employees, volunteers and deprived people.

The FBAO continued to collaborate with external partners to invest in its projects. For instance, the 2020 National Food Collection Day allowed shoppers to make donations via gift cards, converted into non-perishable food. This project was an example of how the inboundoutbound OSI approach helped modify the existing structure. Each involved partner - the network of the FBAO, current external partners (such as large retailers), new participants (such as Epipoli, a digital provider operating in engagement/couponing systems) contributed to share knowledge and experiences to realize the project of National Food Collection. This helped maintain its style but allowed it to be done in the absence of the possibility to meet people and to manage food. Due to the initiative's success, the FBAO is now reflecting if this experimental project could be replicated in the future, demonstrating how the innovation as a strategic response to a crisis can serve to modify future behaviours.

During this period, the FBAO strengthened its partnership with IKEA and McDonald's. Considering that social distancing policies reduced restaurant services, the co-workers of IKEA and McDonald's dedicated part of their working hours to preparing hot meals and packages with food products and delivering them to charity structures, through the territorial associations.

In summary, the FBAO enhanced its pivotal role in OSI (Saebi and Foss, 2015). It involved external sources in absorbing new knowledge and in innovating its activities and the activities of the partners (for example, the traditional ones and the new ones for the National Collection Day). Moreover the FBAO, by transferring knowledge to external partners, training volunteers and external charity organizations, promoted the outbound OSI (for example, education on new procedures). This series of activities presupposes the partial reconfiguration of the well-established FBAO business model with the new components (partners, operations, resources, capabilities). Successful implementation must be assisted by a sequence of incremental adaptations. This process is aimed at testing new ideas in practice (Murray et al., 2010). FBAO materialized this lean transformation process through trials and errors before it achieved a good operational efficiency. "We tried many times to do the same 
thing by adopting different modes until it satisfied us in quality and speed", the General Secretary stated. This persistency surrounded the trial-and-error approach adopted by FBAO. As suggested by Rayna and Striukova (2019) in their multiple case study, the approach was typical of OSI examples.

\section{Discussions}

This paper represents the first attempt to describe the work of the FBAO during a serious crisis affecting both the social and the economic system. It aimed to highlight the new COVID-19 challenges that the FBAO had and has to face. Its management perceives the urgency to change, but it remains difficult to identify the paths for transforming and reshaping its food bank's role, and maintaining its mission, which is considered current and relevant. From the literature (Alexander, 2000), the food bank can manage adaptation by expanding its activities, as other food banks are doing, through focused actions devoted to improving the management techniques and focusing on some core activities.

Considering that a network surrounds the FBAO, the existing FBAO business model serves as an open innovation platform (Saebi and Foss, 2015).

The results elucidate how a crisis, such as the COVID-19 pandemic, stimulates the adoption of OSI practices as a response. Consistent with Chesbrough (2020), OSI assumes an important role in recovery from the COVID-19 aftermath and "can help speed things up" in the social sectors. In particular, openness accelerates the response to critical situations related to COVID-19 and helps support social issues. The urgency in maintaining "social distancing" imposes the necessity to reimagine the processes, and the OSI approach supports process reorganization of one of the most important projects, that is, the National Collection Day. Owing to the network's openness, these processes have been renovated by introducing new partners or creating new fields of collaboration with existing partners. In terms of insideoutside OSI, the FBAO promotes the adoption of new procedures among the territorial associations and, through them, among the charity organizations to handle the increasing scale of activities, reducing the health risk for the volunteers, workers, and assisted people.

Based on previous results and after carefully examining the current literature, this study offers some research propositions that have implications for non-profit organizations facing serious socio-economic crises (like COVID-19), contributing to generalization and extension of our research findings.

Therefore:

P1. The organization that operates as a social network (such as the food bank does) is likely to work as a platform for OSI;

P2. A crisis stimulates the OSI: the more serious the socio-economic crisis, the greater stimulus to OSI;

P3. OSI helps to identify solutions: innovative projects to enrich the social mission or new ways to do the same things;

P4. Through these innovative projects or new ways to do the same things, OSI emerges as a support to face a serious socio-economic crisis more speedily and effectively;

P5. The inbound OSI helps to develop an appropriate attitude to absorb new knowledge for the research of solutions and uses it to propose new ways to develop its mission;

P6. The outbound OSI helps to spread knowledge to the external partners involved in the social mission so that they can enrich their respective area of action;

P7. Combining inbound-outbound OSI, unthinkable innovative solutions are possible with lasting perspective. These are helpful in creating social and economic value and 
$\mathrm{BFJ}$

124,6

1888 in supporting the development of the subjects belonging to the third sectors as an expression of the civil society.

P8. Finally, OSI impacts preserving the social mission allowing it to be pursued in new difficult contexts.

Figure 3 summarizes the interpretative framework regarding the OSI key changes during the COVID-19 crisis.

\section{Conclusions, implications and limitations}

This explorative study aimed to examine the OSI in food banks during the COVID-19 pandemic. It is based on a single case of a food bank operating in Italy, which is unique. Considering that the pandemic has dramatically changed the external environment in which the food bank worked and that it had to find new solutions to continue to solve its mission, this study found that COVID-19 has stimulated the adoption of OSI practices to innovate the food bank behaviour. This was also due to mutual collaborations with external partners, reinforcing some of the existing ones and developing some new ones.

This study provides theoretical and practical implications. Regarding the theoretical implications, first, it contributes to enrich the scarce OSI literature. Moreover, to the best of our knowledge, no other contributions have tied together the OSI and the food bank. This specific study offers insights into how OSI can suggest practical tools to revamp the activities coherently with its social mission and increase the effectiveness of food banks during a crisis.

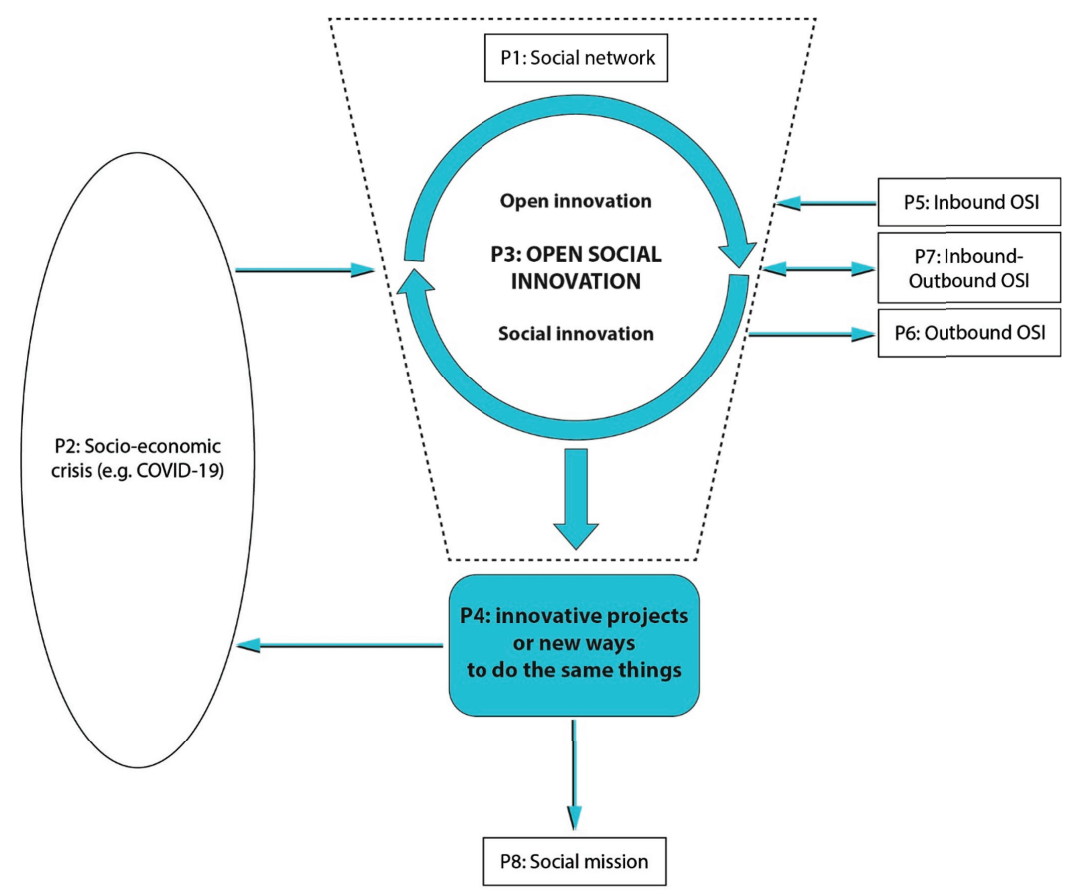

Source(s): Our elaboration 
It underlines the different roles of the inside-out and outside-in OSI so as to modify business models and increase the adaptation capacity. Second, this research builds a rich context in which the social value drivers provided by the OSI are studied. This aspect could be generalized to other types of non-profit organizations. Third, we analysed the food bank as a network that serves as a platform of the OSI, showing how the various involved subjects may contribute and help become conscious of the proposed novelty.

In addition to the theoretical implications, this study proposes some managerial implications by pointing out the relevance of OSI practices in facing a crisis context and addressing the social mission of organizations, the relevance of which becomes greater in such a peculiar situation. Without a strong orientation toward openness and the sharing of experiences with external organizations, it would be very difficult to react quickly to the pandemic, especially given that the situation is one where timely reactions make the difference for involved deprived people. Moreover, this study helps understand the potential role of OSI in dealing with social problems and promoting new initiatives, devoted to meeting evolving needs for the future, reinforcing the organization's original mission, and modifying operations with the emerging social situation. From this perspective, OSI represents an important resource. The managers of the food banks have to be aware of the potential role of OSI and use it as a key strategy to promote open innovation initiatives by collaborating with new external partners and strengthening the existing partnerships, and sharing knowledge and expertise to find innovative solutions.

In order to establish a solid network of relationships, the management of food banks must also develop a deep knowledge about the local environment, intended both as a source of opportunity to be absorbed and exploited, and as a challenge-generator to be coped with. In this perspective, OSI suggests reinforcing the attitude to listen and read any signal from the context. This will help organizations be ready to understand needs and find solutions, involving operators who belong to different industries that are particularly critical in the last stages of the social innovation process. Useful suggestions can be found to cope with their problems and to be socially responsible. Another recommendation for practitioners is not to give up when attempting to "learn on the job" (Rayna and Striukova, 2019, p. 389). A trial-anderror sequence is to be expected before a potential innovation appears. A combination between a trial-and-error disposition and a team able to follow the wave of the food bank's internal changes could be a winning combination.

From a broader perspective, policymakers are encouraged to invest in the promotion of specific interventions aimed at promoting OSI as a weapon and as a strategic response to a crisis. A few examples of such practical actions are research programs, training courses, and agencies that help create a positive environment for developing OSI actions.

Despite the importance of these empirical results and practical implications, this study has some inherent limitations that might be challenged in future research. First, it presents the limitation of the single case study design, which does not help easily generalize the findings; in other words, this research involves a pilot study about the OSI applied to the Italian food bank of the FBAO during a peculiar crisis, identifying the role of OSI in finding and developing solutions. Further studies are needed to extend the number of case studies based on similar organizations in other countries. Second, the number of variables could be expanded by adding other factors related to organizational design (for example, structure, leadership, culture) and the institutional context, its changing role with the new awareness of the seriousness of the situation.

\section{Note}

1. For more detailed information, see BA website https://www.bancoalimentare.it/en 
$\mathrm{BFJ}$

124,6

1890

\section{References}

Adner, R. and Kapoor, R. (2010), "Value creation in innovation ecosystems: how the structure of technological interdependence affects firm performance in new technology generations", Strategic Management Journal, Vol. 31 No. 3, pp. 306-333.

Alexander, J. (2000), "Adaptive strategies of nonprofit human service organizations in an era of devolution and new public management", Nonprofit Management and Leadership, Vol. 10 No. 3, pp. 287-303.

Alkaabneh, F., Diabat, A. and Gao, H.O. (2021), "A unified framework for efficient, effective, and fair resource allocation by food banks using an Approximate Dynamic Programming approach", Omega, Vol. 100, p. 102300.

Anderson, R.M., Heesterbeek, H., Klinkenberg, D. and Hollingsworth, T.D. (2020), "How will country based mitigation influence the course of the COVID-19 epidemic?", The Lancet, Vol. 395 No. 10228, pp. 931-934.

Annosi, M.C., Marzi, G., Ciampi, F. and Rialti, R. (2020), "An ambidextrous approach to practice-based innovation for social product development: lessons from a Dutch company", IEEE Transactions on Engineering Management, pp. 1-12, doi: 10.1109/TEM.2020.2977976.

Bacq, S. and Lumpkin, G.T. (2020), "Social entrepreneurship and COVID-19", Journal of Management Studies. doi: 10.1111/joms.12641.

Baglioni, S., De Pieri, B. and Tallarico, T. (2017), "Surplus food recovery and food aid: the pivotal role of non-profit organisations. Insights from Italy and Germany", VOLUNTAS: International Journal of Voluntary and Nonprofit Organisations, Vol. 28 No. 5, pp. 2032-2052.

Baregheh, A., Rowley, J., Sambrook, S. and Davies, D. (2012), "Food sector SMEs and innovation types”, British Food Journal, Vol. 114 No. 11, pp. 1640-1653, doi: 10.1108/00070701211273126.

Bayona-Saez, C., Cruz-Cázares, C., García-Marco, T. and García, M.S. (2017), "Open innovation in the food and beverage industry", Management Decision, Vol. 55 No. 3, pp. 526-546.

Bazerghi, C., McKay, F.H. and Dunn, M. (2016), "The role of food bank in addressing food insecurity: a systematic review", Journal of Community Health, Vol. 41 No. 4, pp. 732-740.

Belussi, F., Sammarra, A. and Sedita, S.R. (2010), "Learning at the boundaries in an 'Open Regional Innovation System': a focus on firms' innovation strategies in the Emilia Romagna life science industry", Research Policy, Vol. 39 No. 6, pp. 710-721.

Benevolo, C. and Caselli, C. (2000), "Produzione di valore e formula di imprenditorialità sociale: il caso del Banco Alimentare", Sinergie, Rivista di studi e ricerche, CUEIM, Vol. 18 No. 53, pp. 247-266, 0393-5108.

Benevolo, C. and Torre, T. (2002), Tra profit e non profit: creazione di valore e innovazione organizzativa. La realtà del Banco Alimentare, $3^{\circ}$ Workshop dei docenti e ricercatori di Organizzazione Aziendale, L'interpretazione della realtà organizzativa. Unità di impresa, catene di valore, distretti, settori, profit e non profit, Paper Included in the Conference Proceedings, Genova, 7-8 February 2002.

Berner, M. and O'Brien, K. (2004), "The shifting pattern of food security support: food stamp and food bank usage in North Carolina", Nonprofit and Voluntary Sector Quarterly, Vol. 33 No. 4, pp. 655-672.

Bigliardi, B. and Galati, F. (2013), "Models of adoption of open innovation within the food industry", Trends in Food Science and Technology, Vol. 30 No. 1, pp. 16-26.

Boudreau, K. (2010), "Open platform strategies and innovation: granting access vs. devolving control", Management Science, Vol. 56 No. 10, pp. 1849-1872.

Bresciani, S. (2017), "Open, networked and dynamic innovation in the food and beverage industry", British Food Journal, Vol. 119 No. 11, pp. 2290-2293, doi: 10.1108/BFJ-08-2017-0458.

Cavicchi, A. and Santini, C. (2014), Food and Wine Events in Europe. A Stakeholder Approach, Publisher: Routledge, London.

Chalmers, D. (2012), "Social innovation: an exploration of the barriers faced by innovating organisations in the social economy", Local Economy, Vol. 28 No. 1, pp. 17-34, doi: 10.1177/0269094212463677. 
Chesbrough, H. (2003), Open Innovation: the New Imperative for Creating and Profiting from Technology, Harvard Business School Press, Boston, MA, ISBN 9781578518371.

Chesbrough, H. (2020), "To recover faster from Covid-19, open up: managerial implications from an open innovation perspective”, Industrial Marketing Management, Vol. 88, pp. 410-413, doi: 10. 1016/j.indmarman.2020.04.010.

Chesbrough, H. and Bogers, M. (2014), "Explicating open innovation: clarifying an emerging paradigm for understanding innovation", in Chesbrough, H., Vanhaverbeke, W. and West, J. (Eds), New Frontiers in Open Innovation, Oxford University Press, Oxford, pp. 3-28, available at: https:// ssrn.com/abstract $=2427233$.

Chesbrough, H. and Crowther, A.K. (2006), "Beyond high tech: early adopters of open innovation in other industries", R\&D Management, Vol. 36 No. 3, pp. 229-236.

Chesbrough, H. and Di Minin, A. (2014), "Open social innovation”, in Chesbrough, H., Vanhaverbeke, W. and West, J. (Eds), New Frontiers in Open Innovation, Oxford University Press, Oxford, pp. 169-188, Chapter 9.

Chesbrough, H. and Schwartz, K. (2007), "Innovating business models with Co-development partnerships”, Research Technology Management, Vol. 50 No. 1, pp. 55-59.

Cillo, V., Rialti, R., Bertoldi, B. and Ciampi, F. (2019), "Knowledge management and open innovation in agri-food crowdfunding", British Food Journal, Vol. 121 No. 2, pp. 242-258.

Cunningham, J.B. (1997), “Case study principles for different types of cases”, Quality and Quantity, Vol. 31 No. 4, pp. 401-423.

Dahlander, L. and Gann, D.M. (2010), "How open is innovation?”, Research Policy, Vol. 39 No. 6, pp. 699-709.

Dahlander, L., Gann, D.M. and Wallin, M.W. (2021), "How open is innovation? A retrospective and ideas forward", Research Policy, Vol. 50, p. 104218.

Dhanaraj, C. and Parkhe, A. (2006), "Orchestrating innovation networks", Academy of Management Review, Vol. 31 No. 3, pp. 659-669.

Dittrich, K. and Duysters, G. (2007), "Networking as a means to strategy change: the case of open innovation in mobile telephony", Journal of Product Innovation Management, Vol. 24 No. 6, pp. 510-521.

Dyer, W.G. and Wilkins, A.L. (1991), "Better stories, not better constructs, to generate better theory: a rejoinder to Eisenhardt", Academy of Management Review, Vol. 16 No. 3, pp. 613-619.

Eisenhardt, K. (1989), "Building theories from case study research", The Academy of Management Review, Vol. 14 No. 4, pp. 532-550.

Eisenhardt, K.M. and Graebner, M.E. (2007), "Theory building from cases: opportunities and challenges", The Academy of Management Journal, Vol. 50 No. 1, pp. 25-32.

FAO (2019), The State of Food and Agriculture 2019. Moving Forward on Food Loss and Waste Reduction, Rome, 978-92-5-131789-1.

FAO (2020a), Adjusting Business Models to Sustain Agri-Food Enterprises during COVID-19, Rome, doi: 10.4060/ca8996en.

FAO (2020b), COVID-19 and the Risk to Food Supply Chains: How to Respond?, Rome, doi: 10.4060/ca8388en.

FAO, IFAD, UNICEF, WFP and WHO (2020), In Brief to the State of Food Security and Nutrition in the World 2020. Transforming Food Systems for Affordable Healthy Diets, FAO, Rome, doi: 10. 4060/ca9699en.

Farhoud, M., Shah, S., Stenholm, S., Kibler, E., Renko, M. and Terjesen, S. (2021), "Social enterprise crowdfunding in an acute crisis", Journal of Business Venturing Insights, Vol. 15, doi: 10.1016/j. jbvi.2020.e00211.

Ferguson, N.M., Laydon, D., Nedjati-Gilani, G., Imai, N., Ainslie, K., Baguelin, M., Bhatia, S., Boonyasiri, A., Cucunuba, Z. and Cuomo-Dannenburg, G. (2020), Impact of Non-pharmaceutical Interventions (NPIs) to Reduce COVID-19 Mortality and Healthcare Demand, Imperial College, London, doi: 10.25561/77482. 
$\mathrm{BFJ}$

124,6

1892

Ferraris, A., Bogers, M.L. and Bresciani, S. (2020a), "Subsidiary innovation performance: balancing external knowledge sources and internal embeddedness", Journal of International Management, Vol. 26 No. 4, p. 100794.

Ferraris, A., Vrontis, D., Belyaeva, Z., De Bernardi, P. and Ozek, H. (2020b), "Innovation within the food companies: how creative partnerships may conduct to better performances?”, British Food Journal, Vol. 123 No. 1, pp. 143-158, doi: 10.1108/BFJ-07-2019-0502.

Flammini, S., Arcese, G., Lucchetti, M.C. and Mortara, L. (2017), "Business model configuration and dynamics for technology commercialization in mature markets", British Food Journal, Vol. 119 No. 11, pp. 2340-2358.

Fondazione Banco Alimentare Onlus (FBAO) (2020), FEBA, Feeding America e The Global FoodBanking Network: i banchi alimentari non possono farcela da soli!, available at: https://www.bancoalimentare. it/it/news/I-banchi-alimentari-non-possono-farcela-da-soli (accessed 11 April 2021).

Garcia Martinez, M., Lazzarotti, V., Manzini, R. and Sánchez García, M. (2014), "Open innovation strategies in the food and drink industry: determinants and impact on innovation performance", International Journal of Technology Management 23, Vol. 66 Nos 2-3, pp. 212-242.

Garrone, P., Melacini, M. and Perego, A. (2014), “Opening the black box of food waste reduction”, Food Policy, Vol. 46, pp. 129-139.

Gassman, E. and Chesbrough, H. (2010), "The future of open innovation”, R\&D Management, Vol. 40 No. 3, pp. 1-9.

Glaser, B.G. and Strauss, A.L. (1967), Discovery of Grounded Theory: Strategies for Qualitative Research, Aldine, Chicago.

Grimm, R., Fox, C., Baines, S. and Albertson, K. (2013), "Social innovation, an answer to contemporary societal challenges? Locating the concept in theory and practice", Innovation: The European Journal of Social Science Research, Vol. 26 No. 4, pp. 436-455.

Gupta, A., Dey, A. and Singh, G. (2017), "Connecting corporations and communities: towards a theory of social inclusive open innovation", Journal of Open Innovation: Technology, Market, and Complexity, Vol. 3, p. 17.

Henkel, J. (2006), "Selective revealing in open innovation processes: the case of embedded Linux", Research Policy, Vol. 35 No. 7, pp. 953-969.

Hermsdorf, D., Rombach, M. and Bitsch, V. (2017), "Food waste reduction practices in German food retail”, British Food Journal, Vol. 119 No. 12, pp. 2532-2546, doi: 10.1108/BFJ-06-2017-0338.

Holmes, S. and Smart, P. (2009), "Exploring open innovation practice in firm-nonprofit engagements: a corporate social responsibility perspective”, R\&D Management, Vol. 39 No. 4, pp. $394-409$.

Huang, H.C., Lai, M.C., Lin, L.H. and Chen, C.T. (2013), "Overcoming organizational inertia to strengthen business model innovation: an open innovation perspective", Journal of Organizational Change Management, Vol. 26 No. 6, pp. 977-1002.

ISTAT (2021), Nel 2020 un milione di persone in più in povertà assoluta, 4 March 2021, available at: https://www.istat.it/it/files//2021/03/STAT_TODAY_stime-preliminari-2020-pov-assoluta_ spese.pdf.

Komninos, N. (2004), "Regional intelligence: distributed localised information systems for innovation and development", International Journal of Technology Management, Vol. 28 Nos 3-6, pp. 483-506.

Kraus, S., Clauss, T., Breier, M., Gast, J., Zardini, A. and Tiberius, V. (2020), "The economics of COVID19: initial empirical evidence on how family firms in five European countries cope with the corona crisis", International Journal of Entrepreneurial Behavior and Research, Vol. 26 No. 5, pp. 1067-1092, doi: 10.1108/IJEBR-04-2020-0214.

Laborde, D., Martin, W., Swinnen, J. and Vos, R. (2020), “COVID-19 risks to global food security”, Science, Vol. 369 No. 6503, pp. 500-502.

Lichtenthaler, U. (2011), "Open innovation: past research, current debates, and future directions", Academy of Management Perspectives, Vol. 25 No. 1, pp. 75-93. 
Martin, K.S., Wolff, M., Callahan, K. and Schwartz, M.B. (2019), "Supporting wellness at pantries: development of a nutrition stoplight system for food banks and food pantries", Journal of the Academy of Nutrition and Dietetics, Vol. 119 No. 4, pp. 553-558.

Matricano, D., Candelo, E., Sorrentino, M. and Martínez-Martínez, A. (2019), "Absorbing in-bound knowledge within open innovation processes. The case of Fiat Chrysler Automobiles", Journal of Knowledge Management, Vol. 23 No. 4, pp. 786-807.

Menke, C. and Raith, M. (2017), "Culture and its effects on commercial vs social entrepreneurship: a macro and micro level analysis", Academy of Management Annual Meeting Proceedings. doi: 10. 5465/AMBPP.2017.15823abstract.

Michelini, L., Principato, L. and Iasevoli, G. (2018), "Understanding food sharing models to tackle sustainability challenges", Ecological Economics, Vol. 145, pp. 205-217.

Midgley, J.L. (2014), “The logics of surplus food redistribution”, Journal of Environmental Planning and Management, Vol. 57 No. 12, pp. 1872-1892.

Moulaert, F. and MacCallum, D. (2019), Advanced Introduction to Social Innovation, Edward Elgar, Cheltenham.

Mulgan, G. (2006), "The process of social innovation", Innovations: Technology, Governance, Globalization, Vol. 1 No. 2, pp. 145-162.

Mumford, M.D. (2002), "Social innovation: ten cases from Benjamin Franklin", Creativity Research Journal, Vol. 14 No. 2, pp. 253-266.

Murray, R., Caulier-Grice, J. and Mulgan, G. (2010), The Open Book of Social Innovation, Young Foundation, London.

Nichols-Casebolt, A. and Morris, P.M. (2002), "Making ends meet: private food assistance and the working poor", Journal of Social Service Research, Vol. 28 No. 4, pp. 1-22.

Nieto, M.J. and Santamaría, L. (2007), "The importance of diverse collaborative networks for the novelty of product innovation", Technovation, Vol. 27 Nos 6-7, pp. 367-377.

Penco, L., Torre, T. and Scarsi, R. (2019), "Does strategic orientation influence strategy formulation and organisational design in Italian food medium sized enterprises? The role of the family", British Food Journal, Vol. 122 No. 5, pp. 1397-1419.

Principato, L., Secondi, L., Cicatiello, C. and Mattia, G. (2020), "Caring more about food: the unexpected positive effect of the Covid-19 lockdown on household food management and waste", SocioEconomic Planning Sciences, Vol. 100953, doi: 10.1016/j.seps.2020.100953.

Randhawa, K., Wilden, R. and West, J. (2019), "Crowdsourcing without profit: the role of the seeker in open social innovation”, R\&D Management, Vol. 49 No. 3, pp. 298-317.

Rayna, T. and Striukova, L. (2019), "Open social innovation dynamics and impact: exploratory study of a fab lab network", R\&D Management, Vol. 49 No. 3, pp. 383-395.

Ritter, T. and Gemunden, H.G. (2003), "Network competence: its impact on innovation success and its antecedents", Journal of Business Research, Vol. 56 No. 9, pp. 745-755.

Rohrbeck, R., Hölzle, K. and Gemünden, H.G. (2009), "Opening up for competitive advantage - how Deutsche Telekom creates an open innovation ecosystem”, R\&D Management, Vol. 39 No. 4, pp. $420-430$.

Rothwell, R. (1994), "Towards the fifth-generation innovation process", International Marketing Review, Vol. 11 No. 1, pp. 7-31.

Saebi, T. and Foss, N.J. (2015), "Business models for open innovation: matching heterogeneous open innovation strategies with business model dimensions", European Management Journal, Vol. 33 No. 3, pp. 201-213.

Scheidgen, K., Gümüsay, A.A., Günzel-Jensen, F., Krlev, G. and Wolf, M. (2021), "Crises and entrepreneurial opportunities: digital social innovation in response to physical distancing", Journal of Business Venturing Insights. doi: 10.1016/j.jbvi.2020.e00222. 
$\mathrm{BFJ}$

124,6

1894

Schepis, D., Purchase, S. and Butler, B. (2021), "Facilitating open innovation processes through network orchestration mechanisms", Industrial Marketing Management, Vol. 93, pp. 270-280.

Siggelkow, N. (2001), "Change in the presence of fit: the rise, the fall, and the renaissance of liz claiborne", Academy of Management Journal, Vol. 44 No. 4, pp. 838-857.

Siggelkow, N. (2007), "Persuasion with case studies", Academy of Management Journal, Vol. 50 No. 1, pp. 20-24.

Tarasuk, V., Dachner, N. and Loopstra, R. (2014), "Food banks, welfare, and food insecurity in Canada”, British Food Journal, Vol. 116 No. 9, pp. 1405-1417, doi: 10.1108/BFJ-02-2014-0077.

Tardivo, G., Santoro, G. and Ferraris, A. (2017), "The role of public-private partnerships in developing open social innovation: the case of Google Glass4Lis", World Review of Entrepreneurship, Management and Sustainable Development, Vol. 13 Nos 5-6, pp. 580-592.

Teron, A.C. and Tarasuk, V.S. (1999), “Charitable food assistance: what are food bank users receiving?", Canadian Journal of Public Health/Revue Canadienne de Sante'e Publique, Vol. 90 No. 6, pp. 382-384.

Torre, T. (2000), "Le risorse umane quale fattore critico di successo per lo sviluppo delle aziende non profit: lo Human Resource Management dei dipendenti”, in Manfredie Zangrandi, F.A. (Ed.), Aziende Non Profit. Dall'eterogeneità All'economicità. Riflessioni Ed Esperienze Innovative, Egea, Milano, pp. 131-144, ISBN 88-238-0639-9.

Traitler, H., Watzke, H.J. and Saguy, I.S. (2011), "Reinventing R\&D in an open innovation ecosystem”, Journal of Food Science, Vol. 76 No. 2, pp. R62-R68.

van der Horst, H., Pascucci, S. and Bol, W. (2014), "The 'dark side' of food bank? Exploring emotional responses of food bank receivers in the Netherlands", British Food Journal, Vol. 116 No. 9, pp. 1506-1520.

Vanhaverbeke, W. (2006), "The inter-organisational context of open innovation", in Chesbrough, H., Vanhaverbeke, W. and West, J. (Eds), Open Innovation: Researching a New Paradigm, Oxford University Press, Oxford, pp. 205-219.

West, J. and Bogers, M. (2014), "Leveraging external sources of innovation: a review of research on open innovation”, Journal of Product Innovation Management, Vol. 31, pp. 814-831.

West, J. and Bogers, M. (2017), "Open innovation: current status and research opportunities", Innovation: Organisation and Management, Vol. 19 No. 1, pp. 43-50.

West, J., Vanhaverbeke, W. and Chesbrough, C. (2006), "Open innovation: a research agenda", in Chesbrough, H., Vanhaverbeke, W. and West, J. (Eds), Open Innovation: Researching a New Paradigm, Oxford University Press, Oxford, pp. 285-307.

Westley, F. and Antadze, N. (2010), "Making a difference: strategies for scaling social innovation for greater impact", The Innovation Journal: The Public Sector Innovation Journal, Vol. 15 No. 2, pp. 1-19.

Yin, R.K. (1994), "Discovering the future of the case study. Method in evaluation research", Evaluation Practice, Vol. 15 No. 3, pp. 283-290, doi: 10.1177/109821409401500309.

Zeng, S.X., Xie, X.M. and Tam, C.M. (2010), "Relationship between cooperation networks and innovation performance of SMEs", Technovation, Vol. 30 No. 3, pp. 181-194.

\section{Corresponding author}

Lara Penco can be contacted at: lara.penco@economia.unige.it

For instructions on how to order reprints of this article, please visit our website:

www.emeraldgrouppublishing.com/licensing/reprints.htm

Or contact us for further details: permissions@emeraldinsight.com 